\title{
A Cultural Journey of Eileen Chang's Half Lifelong Romance-A Study of Karen Kingsbury's English Translation
}

\author{
Naizhuo Kong \\ Foreign Language Teaching and Research Press, Peking, China \\ Yuanfei Yao \\ West China Normal University, Nanchong, Sichuan, China
}

\begin{abstract}
Half Lifelong Romance translated and introduced by Karen Kingsbury, a translation research expert of Eileen Chang, was published by Penguin Press in 2012. This modern and contemporary female literature has been known by Western readers from the eastern continent, and its cultural journey has crossed the language barrier. Based on this, this paper will explain the cultural travel of Eileen Chang's English version from the perspective of classics, translator's view and Eugene Nida's division of culture, in order to bring some enlightenment to the translation of Chinese and English studies.
\end{abstract}

Index Terms - cultural journey, Karen Kingsbury, Half Lifelong Romance

\section{INTRODUCTION}

Le Daiyun said: "to go to the world, Chinese literature should participate in the dialogue of world literature. Only mutual understanding can lead to dialogue, and only dialogue can lead to mutual understanding." (Le Daiyun, 2014, p.64). If Chinese literature wants to talk with the world and connect with the world, translation is necessary. Since ancient times, "translation has been acting as an intermediary and bridge between different languages and cultures. Translation is also the exchange of cultural content in different language containers." (Wang Yinchong, 2018, p.ix). However, the successful translation of a work is bound to cross the cultural boundary, in which translation becomes a process of transformation. This process is called cultural journey.

In 2007, Eileen Chang's novel love in a fallen city was translated by Karen Kingsbury, which made a great sensation when it was published and was included in the famous Penguin Classic Library in the UK. Soon, another translation of Karen Kingsbury, Half a Lifetime Romance, entered the library. The successful translation of Eileen Chang's translation is mainly attributed to Karen Kingsbury's translation view. "In an interview, Karen Kingsbury talked about the translation of Love in the City. She believed that the novel would attract readers because of its vivid language, profound philosophy, rich social environment, distinct characters and complete story structure." (Chou Jing, 2015). Karen Kingsbury said that these factors are the main reasons why she chose love in a fallen city as the translation theme and research theme. It can be seen that the translator's "cultural consciousness" is particularly important in the process of translating and introducing novels. In analyzing Howard Goldblatt' s English translation of Sandalwood Death by Mo Yan, Lu Qiaodan holds that the cultural journey is to show the charm of one's own culture, and at the same time to integrate harmoniously into foreign cultures"(Lu Qiaodan, 2015, p.48). This process can be briefly summarized as seeking common ground while reserving differences, which is undoubtedly the same as the "literary dialogue" of Le Daiyun's.

The successful translation and introduction of Eileen Chang's Half a Lifetime Romance means the classic status of this work in modern and contemporary Chinese literature, which is the primary guarantee of cultural travel. Therefore, this paper attempts to analyze the travel path of the novel in two different cultures and explore the translation strategies adopted by Karen Kingsbury in different cultural backgrounds, in order to bring enlightenment to the translation of the novel.

\section{DISCUSSIONS \& ANALYSIS}

\section{A. The Classicality of Half a Lifetime Romance}

The classic of literature is an important factor to ensure that a work can travel successfully in a foreign culture. What is the classicality of literature? In the words of E. Dean Kolbas, "the unique cognitive value of literary works, as well as their objective truth, are embedded in their formal aesthetic characteristics." (E. Dean Kolbas, 2001, p.114). A successful work must have a unique aesthetic value and exist in the form of expression chosen by literature. In other words, it is the perfect combination of story and form. And Half a Lifetime Romance is such a work, its form of 
discourse expression and the content of the story is a perfect combination. Eileen Chang imitates different characters to narrate, and any ideological connotation and enlightenment are integrated into the unity of form and story.

The classic feature of the novel is Eileen Chang's "uniqueness of creation process, theme and character setting" (Yang Pengfei, 2001, p.58). The novel was first named Eighteen spring and later Half a Lifetime Romance. Eileen Chang added political color to the literary writing of eighteen spring, so when she arrived in the United States, she rewritten it, breaking the traditional love hate tangle of spoony men and women, and named it Half a Lifetime Romance. This work is a reinterpretation and interpretation of Eileen Chang's personal destiny, and it is also her creative style of breaking vulgar comedy. Secondly, in terms of the choice of theme, Half a Lifetime Romance is a familiar theme of Eileen Chang, which reveals the philosophy of nihilism. In a novel called love, she said, "meet the people you want to meet among millions of people, in thousands of years, in the boundless wilderness of time, there is no earlier or later step, just happened to be on, there is no other words to say, but gently ask, 'Oh, are you here?' " (Eileen Chang, 1992). From this, we can find that Chang's view of love is a kind of nihility of fireworks passing away. Finally, the characters in Eileen Chang's works, especially the male characters, are often of the same type. No matter Shijun or Zhu Hongcai, they are all "children's corpses soaked in wine vat"(Eileen Chang,1992). Although the appearance has been blistered, the heart is still the child's mind. In one of the key elements of the story--action, these male characters have no idea what responsibility, obligation and responsibility are. But in Eileen Chang's characterization, it is precisely because of the impotence of men that women's miserable life is created, rather than directly through a large number of descriptions of women's painful life, to make readers feel directly. In this emotional line between Manzhen and Shijun, it can be said that Shijun is the main cause of tragedy. If he can be brave and take the initiative to eliminate misunderstanding, if he can be faithful to love and believe in Manzhen's view of love how could their relationship be only "half life"? Therefore, although the male characters in the novel for the first time are quite different from those in the past on the surface, showing the new social features and the new characters under the historical conditions, the essence of them has not changed at all. Their inner and spiritual weakness and cowardice are the reflection and expression of the collective unconsciousness of the personality defects left over from the feudal patriarchal society for thousands of years.

Eileen Chang, with her keen observation and artistic plot setting, makes the work Half a Lifetime Romance truly classic. The intrinsic artistry and classics of the novel become the beginning of the successful translation of the novel and the first step of the cultural travel of the novel.

\section{B. A study of Karen Kingsbury's View of Translation}

In the process of translation study, the translator is also an easy to be ignored research object. People paid more attention to the author of literary works than the translator. However, the translator is the bridge between the text, the reader, the author and the editor. As a cultural coordinator, the translator should endeavor to balance and coordinate the eastern and western cultures so that the translation can not only reflect the charm of the eastern culture, but also be accepted by the western culture. Translation studies have become a major trend in translation studies, especially in translation sociology, translation history and translator decision-making. It is this fluidity and contradiction that makes the study of translators more meaningful and interesting. There are rational and irrational aspects in the choice of translators. They are living in a complex and changing historical society. They are not only faced with the requirements of translation norms and translators' ethics, but also have different abilities, beliefs, responsibilities and preferences.

Besides, translators' daily life often influences their choice of objects, ideas and strategies, and some even play a key role in the process. This kind of double experience, repeated cultural shock, open family environment and good education background shaped her as a "mixed culture child". ${ }^{[9]}$ Therefore, the translator's translation strategy plays an important role in promoting the cultural journey of his works.

As an English translator of Eileen Chang's novels, in the selection of translation materials, the translator's subjective commonness and external objective conditions, Karen Kingsbury plays an important role. During his study at Columbia University, she was deeply influenced by Xia Zhiqing, her supervisor, and gradually began to contact Eileen Chang's works. Eileen Chang's Half a Lifetime Romance contains unique writing and wording, psychological insight, rich emotion and outlook on life, which can help me better understand what self-esteem, encounter and desire are, which causes the resonance between Karen 's emotion and her works, and becomes one of the reasons why she chooses to translate it; in addition, the novel is rich in philosophical thoughts, distinctive character, etc., and is self-contained It has never been translated since it came out, which is another reason why she translated Half a Lifetime Romance . At the same time, Eileen Chang's writing style is influenced by western literary works. In terms of the setting of characters in the novel, Chang's discourse has a similarity with some works, especially the work, H. M. PulHam, Esqire written by J. P. Marquand, an American Pulitzer Prize winning writer. And so it indicates that the target language readers will adapt to and accept the work well and quickly.

In a word, Karen Kingsbury's view of translation can be expressed in two very appropriate metaphors, that is, "the metaphor of pianist" and "the metaphor of film"(Tan Jianghua, 2011, p.25). She believes that translation is the translator's interpretation of subjectivity, only a reader's interpretation. The translator is only on his own to convey the psychological and sensory stimulation of his works to himself (and a large number of Chinese readers, of course). "The translation between languages is not a mechanical transformation, like changing the melody from one tune to another," she said. It is a kind of interpretation, which is the behavior of personal subjective mind to transform art materials from one medium to another. 


\section{A Journey Abroad under Nida's Cultural Classification}

In the last century, the study of translation theory has been further developed, and it appears that cultural school of translation, which includes Evan Zohar's view on the operation of multiple systems, Lefevere's rewriting, Herman $\mathrm{s}$ concept of manipulation, Evan Zohar, Toury's terms of multiple systems, formal Library, classics, norms, etc Lefevere's "three factors" theory of "ideology", "Poetics" and "patronage"(Yaoyuanfei\& Li Congli, 2019). In addition, Eugene A. Nida is a famous linguist. His previous studies, "from the perspective of linguistics, put forward many important theories such as 'functional equivalence', and then extended his translation theory to the field of culture" (Yaoyuanfei\& Li Congli, 2019).

In the new edition of principles of comparative literature, Le Daiyun proposed that "the research of comparative literature has risen to the research of comparative culture"(Le Daiyun, 2014). Therefore, according to our national strategy, One Belt and Road, the cultural go global strategy, translation should also rise to the deep level of culture. Therefore, "the academic study of translation should regard it as a kind of cultural information exchanged in a symbolic way under the dual cultural background between the source language and the target language." (Yao Yuanfei\& Li Congli, 2019) And the work from one language to another is a cultural change. From the perspective of Nida's cultural classification to analyze the translator's translation strategy, we can see the cultural journey of a work from different cultural backgrounds. Next, we will classify Nida culture into ecological culture, material culture, religious culture, social culture and language culture, and analyze these five points

\section{Ecological culture}

"Ecological culture involves the names of a nation, the climate and so on." (Nida Eugene A, 1964)

“这一向正是酷热的秋老虎的天气, 这一天傍晚倒凉爽了些。”(Eileen Chang, 2011).

"The weather had been hot for several days running, the last blast of early autumn heat, but temperatures had dropped this evening." (Kingsbury, 2012).

““秋老虎” is the short-term hot weather in China after the autumn. If the translator handles this climate with literal translation, according to the treatment of place names, such as: 六安 literally translated as 'Liu'An', indeed foreign readers will pronounce its mandarin, but the word in the work, it is , Lu'An" (Yaoyuanfei\& Li Congli, 2019). That is why literature translation should not only consider language problems, but its subtext meaning. "Based on this, the translator used the strategy of free translation when dealing with the translation of such folk sayings such as '秋老虎', abandoning the literal meaning of the original text, and adopting the method of "dynamic equivalence" to make the translation express ideas and language functions". (Yaoyuanfei\& Li Congli, 2019)

\section{Material culture}

"Material culture is the economic life and daily use of a nation, production tools, and science and technology." (Nida Eugene A, 1964)

“曼桢又继续说下去, 道: “我姊姊那时候中学还没有毕业, 想出去做事, 有什么事是她能做的呢? 就是找得 到事，钱也不会多，不会够她养家的。只有去做舞女。”(Eileen Chang, 2011).

“"my sister hadn't finished secondary school,' Manzhen continued. 'what kind of job could she get? Even if she did get a job, it wouldn't pay much. Not enough to support a family. Her only choice was to become a taxi-dancer." (Kingsbury, 2012).

"The translator translates the "舞女"(the phrase means a dancing girl) into "taxi-dancer". Before the May Fourth Movement, the dancers were invisibly called prostitutes, but not professional prostitutes. The dancers here refer to the services of accompanying dances at work, as well as sexual services as well. The translator used taxi-dancer, without the use of the prototype, to perfectly interpret the meaning of the dancer here" (Yaoyuanfei\& Li Congli, 2019). The symbolic of taxi in English or Chinese produces the image which whoever only pays money to take.

\section{Religious culture}

“可是对于年轻人, 三年五载就可以是一生一世。他和曼桢从认识到分手, 不过几年的工夫, 这几年里面却经 过这么许多事情, 彷佛把生老病死一切的哀乐都经历到了。”(Eileen Chang, 2011).

"But in that brief span, they'd had a full measure: all the joy and the sorrow that comes with (as the old saying has it) 'birth, old age, illness, death.” (Kingsbury, 2012).

“一生一世” from Cao Xueqin's "Dream of Red Mansions" refers to a lifetime. "Religious culture includes a nation's religious beliefs, religious systems, religious writings, religious systems and regulations." (Nida Eugene A, 1964) "This view is a kind of Buddhist monastic view in "Dream of Red Mansions", which is considered to be that Life is the number of years you to live and Life is your reincarnation" (Yaoyuanfei\& Li Congli, 2019). Buddhism believes that people will reincarnate after death. The values, attitudes and ethics of Anlgo-American people are greatly influenced by these three religious ideas (Protestantism, Catholicism and Judaism). And so when thinking of translating a religious problem, the translator adopts a domestication translation strategy, which makes the foreign religion clear or easy to understand.

\section{Social culture}

“不会是敲我们的竹杜吧?”(Eileen Chang, 2011).

“'Don't you think the price should be lower here, out on the edge of town?' Shuihui said. 'Are they cheating us? "”(Kingsbury, 2012). 
“敲竹杜” is a dialect in Chinese proverbs. Its speech is derogatory, which means deceives somebody. The expression in the Anglo-American social culture is little known. It in this context is very literariness. "To cheat us" indeed is its direct meaning, but the Eileen Chang employs direct speech to ape Manzhen's tone for reflecting the character characteristics. "The traditional customs, lifestyles, characteristics and forms of social activities, habitual titles of individuals, society and classes." (Nida Eugene A, 1964). "The translator domesticates it in order to take care of the reading habits of Western readers when dealing with Chinese and Western cultural translations". (Yaoyuanfei\& Li Congli, 2019). However, the way to handle the words is less artful than source text.

\section{Language and culture}

"Language culture is the language itself as a part of culture. It also causes translation problems. Since the two languages belong to two different language systems, the translation will design different language features, and these different characteristics may be reflected in the voice, Morpheme, vocabulary and syntax." (Nida Eugene A, 1964)

“过年吃蛤蚛, 大概也算是一个好口彩——算是元宝。”(Eileen Chang, 2011).

“Clams at New Year - I'll bet it's for good luck. They 're yuanbao, little lumps that look like a stack of coins.”(Kingsbury, 2012).

Yuanbao is a cultural symbol of China's prosperity. In this context, regarding dumplings as Yuanbao means eating them and the life will be better. From this we can find the hardship of supporting Manzhen's family, but at the same time we can see the intention of Eileen Chang's role building, that is, women assume the social ability of men, which implies women's awakening. Therefore, Yuanbao's literal translation is Yuanbao, where the translator only understands the language level of the text and fails to live up to the author's good intentions. In terms of translation strategy, I believes that due to the good strategy of literal translation, the translator must annotate the subtext of this image.

In the process of English translation, the translator should not only transfer the characters and symbols, but also be a cultural coordinator. In the process of translating Chinese novels into English, the translator needs to perfectly reproduce the eastern culture to the Western readers and resolve the complex conflicts between the eastern and Western cultures. The translator manipulates and rewrites the original text by relying on his own cultural view, bilingual ability, translation thought, but does not forget to consider the reading experience of the target language readers. His/her proper "manifestness" will naturally achieve the success of translation and make his/her translation win the favor of overseas market. To a certain extent, the translator will add his/her own cultural view to the translation, and the final form of the translation will be "original + original cultural background + translation + translation cultural background + original author's temperament and style + translator's temperament and style mixture".(Wang Ning, 2020).

It can be seen from the above that in dealing with the translation under different cultural background, translators adopt the translation strategy of combination of, besides foreignization and domestication, and annotate, to "try to keep the language and cultural differences of the original text, and bring the target readers into the original language and culture, just like an audience enjoying a music abroad. However, when some cross-cultural cannot be foreignized, in order to take care of the reading habits of the target readers" (Yaoyuanfei\& Li Congli, 2019), they have to adopt the domestication translation strategy. The translator should not only be able to convey the exotic customs, but also be faithful to the deep meaning of the source text. Otherwise, it only conveys linguistic equivalence. Literary translation should not only look at the iceberg floating on the water, but also fully discover the great literary significance under the iceberg.

\section{CONCLUSION}

For a long time, the essence and connotation of a large number of excellent Chinese literary works have not been recognized by Western readers, and one of the important factors hindering Chinese literature from going to the world is translation. Most scholars believe that China lacks translators who are proficient in both Chinese and English, which results in the poor translation and the difficulty of Chinese literature going to the world. Language is not the main factor for Chinese literature to go to the world effectively. That is what kind of translation strategy. As Wang Ning called for, "in the process of effectively translating Chinese literature into the English world and even the whole world, we should pay more attention to the cultural acceptance factors of the target language, which is crucial for the spread of culture and literature overseas."(Liu Mingqing, 2007, p.12). Translation is the ladder of Chinese literature to the world stage. Nevertheless, the process is neglected all the time.

Eileen Chang's Half a Lifetime Romance is just a representative work written by Oriental women. Its internal artistry and ideological dimension are in harmony, forming the classic of the novel and the beginning of the novel's cultural journey. In the process of translation, Karen Kingsbury turned complicated cultural factors and translation strategies into a beautiful piano melody. According to the analysis of Nida's cultural classification, we can further find out how Half a Lifetime Romance travels in two cultural worlds. It can be said that Karen's translation has injected new vitality into Eileen Chang's work, and the journey of Half a Lifetime Romance in the English world has continued the artistic value of this work. It is the crossing and fusion of two cultures, and finally it is reborn on the world stage. 


\section{REFERENCES}

[1] Chou Jing. Karen Kingsbury: my choice of translation Theme. (2015). Web Transcription Tool. http://www.catl.org.cn/2015-12/20/content_37359643.htm, (accessed 12/20/2015).

[2] E. Dean Kolbas. (2001). Critical Theory and the Literary Canon. Boulder: Westview Press.

[3] Eileen Chang. Love. (1992). Collected works of Eileen Chang. Hefei: Anhui literature and Art Press.

[4] Eileen Chang. (2011). Half a Lifetime Romance. Peking: Peking October literature and Art Press.

[5] Eileen Chang. (2012). Half Lifelong Romance Trans. By Karen Kingsbury. London: Penguin group.

[6] Eileen Chang. (1992). Flower withering. Collected works of Eileen Chang. Hefei: Anhui literature and Art Press.

[7] Le Daiyun. (2014). A new edition of the principles of Comparative Literature. Peking: Peking University Press.

[8] Liu Miqing. (2007). On Cultural Translation. Peking: China Foreign Translation Publishing Company.

[9] Lu Qiaodan. (2015). The cultural journey of the novel Sandalwood Death by Mo Yan in the English world. Novel Review,4, 48-55.

[10] Nida Eugene A. (1964). Language in Culture and Society. Dell Hymes: Allied Publishers pvt.

[11] Tan Jianghua. (2011). Language pianist: the translation view of Karen Kingsbury, an American Sinologist. Journal of Chongqing Jiaotong University (Social Sciences, 33,24,121-125.

[12] Wang Ning. (2020). how can Chinese literature effectively go to the world. Web Transcription Tool. http://www.ts-pioneer.com/wenhua/20200421159138.html, (accessed 4/21/2020).

[13] Wang Yinchong. (2018). A study of English translation of Chinese Novels. Peking: Foreign Language Teaching and Research Press.

[14] Yaoyuanfei\& Li Congli. (2019). A Cultural Journey of Eileen Chang's Half Lifelong Romance--A Study of Karen Kingsbury's English Translation. International Journal of Liberal Arts and Social Science, 7, 33-42.

[15] [15] Yang Pengfei. (2001). Half a Lifetime Romance_Eileen Chang's most unique work. Journal of Changchun University, $21,58-59$.

Naizhuo Kong was born in Qufu, Shandong Province, PR China. He, MA, associate professor, deputy managing director of Higher English Education Publishing, Foreign Language Teaching and Research Press, has presided over or participated in the development and publication of many nation-wide used textbooks, and is responsible for many key projects in the press. His research interests include training of editing talents, textbook studies, English linguistics \& teaching, translation studies, etc.

Yuanfei Yao (corresponding author) was born in Yuxi, China in 1991. He is a graduate at West China of Normal University. His research interests include Anglo-American literature, Linguistics and Translation. 